\title{
Interferência de Plantas Daninhas sobre o Crescimento Inicial DE Coffea arabica
}

\author{
Weed Effect on the Initial Growth of Coffea arabica
}

\author{
FIALHO, C.M.T. ${ }^{2}$, FRANÇA, A.C. ${ }^{3}$, TIRONI, S.P. ${ }^{4}$, RONCHI, C.P. ${ }^{5}$ e SILVA, A.A. ${ }^{6}$
}

\begin{abstract}
RESUMO - Objetivou-se com este trabalho avaliar os efeitos da interferência de plantas daninhas, em diferentes densidades de infestação, sobre o crescimento de plantas jovens de café arábica. Mudas de café, cultivar Mundo Novo, foram transplantadas, no estádio de quatro a cinco pares de folhas completamente expandidas, para vasos com capacidade de $25 \mathrm{dm}^{3}$. O experimento foi conduzido em casa de vegetação em blocos casualizados, em esquema fatorial (4 x 4); o primeiro fator foi composto por espécies de plantas daninhas (Digitaria horizontalis, Brachiaria decumbens, Brachiaria plantaginea e Mucuna aterrima), e o segundo, por densidades dessas espécies (zero, dois, quatro e seis plantas por vaso), com quatro repetições. O plantio das espécies daninhas foi realizado 60 dias após o transplantio do café (O DAT). Nesta data e no dia do encerramento do experimento, aos 90 DAT, determinaram-se a altura, a área foliar e o diâmetro do caule da planta de café, para cálculo do incremento dessas variáveis. Aos 90 DAT, determinou-se a matéria seca da parte aérea e radicular do café e das plantas daninhas e a densidade radicular do café. Utilizando esses resultados, estimou-se a razão de massa foliar, razão de massa caulinar, razão de massa radicular, razão de área foliar e a razão sistema radicular/parte aérea das plantas de café. A espécie $M$. aterrima foi a que mais reduziu a taxa de crescimento, a área foliar, a matéria seca do caule e das folhas e o diâmetro do caule do café. Entre as gramineas, B. plantaginea foi a que mais reduziu a taxa de crescimento, área foliar, diâmetro do caule e densidade radicular do café. Ocorreu relação negativa entre a densidade de plantas daninhas e as variáveis de crescimento e com a razão de massa radicular e razão sistema radicular/parte aérea.
\end{abstract}

Palavras-chave: café arábica, competição, manejo integrado, período de convivência, sustentabilidade.

ABSTRACT - The goal of this work was to evaluate the effects of weeds on the growth of young Arabica coffee plants, at different densities of infestation. Seedlings of Mundo Novo coffee cultivar were transplanted at the stage of four to five pairs of completely expanded leaves, to pots with capacity of $25 \mathrm{dm}^{3}$. The experiment was arranged in a randomized block in factorial design (4 $x$ 4), with four weed species (Digitaria horizontalis, Brachiaria decumbens, Brachiaria plantaginea and Mucuna aterrima) at four planting densities coexisting with coffee (zero, two, four, and six plants per pot), with four replications. The weed species were planted 60 days after the coffee plant transplanting (O DAT). On this date, and on the day the experiment was concluded, at $90 \mathrm{DAT}$, height, leaf area and stem diameter of the coffee plants were determined. At 90 DAT, measurements were also performed to determine the increase in height, leaf area and stem diameter of the coffee plants, as well as shoot and root dry matter of the coffee plants and weeds and coffee plant root density. Based onthese data, estimations were made for leaf mass ratio, stem mass ratio, root mass ratio, leaf area ratio and root system/shoot ratio of the coffee plants. The species M. aterrima presented the highest reduction rate for plant height, leaf area, dry matter of stem and

1 Recebido para publicação em 27.7.2010 e na forma revisada em 18.2.2011.

2 Engà-Agr ${ }^{\mathrm{a}}$., M.Sc., Doutoranda, Dep. de Fitotecnia, Universidade Federal de Viçosa - DFT/UFV, 36570-000 Viçosa-MG, $<$ cintiamtfialho@yahoo.com.br>; ${ }^{3}$ Eng $^{-}-$Agr $^{\circ}$., D.Sc., Professor, Universidade Federal dos Vales do Jequitinhonha e Mucuri UFVJM, Faculdade de Ciências Agrárias, Campus II, Rodovia MGT 367, Km 583, no 5000, Bairro Alto da Jacuba, $39100-000$

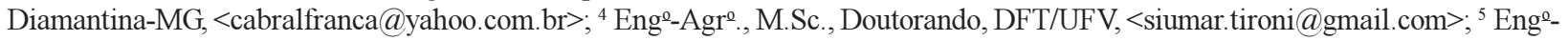
Agro ${ }^{\circ}$, D.Sc., Professor, Universidade Federal de Viçosa, Campus Rio Paranaíba - UFV-CRP, Rod BR 354, km 310, Caixa Postal 22, 38810-000 Rio Paranaíba-MG, <claudiopagotto@ufv.br>; ${ }^{6}$ Eng$^{-}-$Agr $^{\circ}$., D. Sc., Professor Associado, DFT/UFV, <aasilva@ufv.br>.

Planta Daninha, Viçosa-MG, v. 29, n. 1, p. 137-147, 2011 
leaves and girth diameter of the coffee plants. Among the grasses, B. plantaginea presented the highest reduction rate for plant height, leaf area, girth diameter and root density. A negative relation was observed between weed increase and growth variables, and between root mass ratio and root system/shoot ratio.

Keywords: Arabica coffee, competition, integrated management, coexistence period, sustainability.

\section{INTRODUÇÃO}

A cultura do café no Brasil ocupa área superior a 2,3 milhões de hectares, com produção na safra de 2009 de 36,9 milhões de sacas, sendo o maior produtor e exportador de café mundial (CONAB, 2009). Contudo, a produtividade média brasileira de café é baixa $\left(18,28\right.$ sacas ha $\left.^{-1}\right)$, considerando que o potencial produtivo das variedades é superior a 40 sacas ha ${ }^{-1}$ de café beneficiado (CONAB, 2009). Entre os fatores que contribuem para a baixa produtividade do cafeeiro encontra-se a interferência das plantas daninhas.

A fase inicial de crescimento do cafeeiro - compreendida entre o transplantio das mudas e o segundo ano pós-plantio - é considerada a mais sensivel à interferência das plantas daninhas, sobretudo quando estão na linha de plantio da cultura (Ronchi et al., 2003; 2007). Além disso, devido à rusticidade das plantas daninhas, estas se destacam na rapidez e eficiência da utilização dos recursos do ambiente, levando vantagem sobre o crescimento das culturas. Ronchi et al. (2007) observaram que plantas de café tiveram menor acúmulo da matéria seca do sistema radicular quando se desenvolveram na presença de plantas daninhas, como Bidens pilosa e Sida rhombifolia.

As plantas daninhas normalmente são vistas pelos cafeicultores apenas como competidoras por água, luz e nutrientes e, por isso, são erradicadas do cafezal. Esse fato deve-se à divulgação de resultados de pesquisas (Toledo et al., 1996; Ronchi et al., 2003) que evidenciaram a interferência negativa das plantas daninhas sobre o cafeeiro. Atualmente, temse nova visão dos resultados das pesquisas citadas, considerando também o efeito benéfico dessas espécies não cultivadas. Portanto, evidencia-se nova fase nas pesquisas sobre a competição com plantas daninhas, em que conceitos de manejo integrado precisam ser explorados (Mortensen et al., 2000).
Relatos da experiência do uso de faixas de controle de plantas daninhas (Dias et al., 2004; Souza et al., 2006), adubo verde (Erasmo et al., 2004), entre outras em consórcio com o café, têm comprovado a necessidade do manejo integrado, uma vez que as espécies cultivadas em consórcio com a cultura principal, em diferentes densidades, são capazes de suprimir a interferência de plantas daninhas na entrelinha da cultura (Baumann et al., 2001). Dentre outras vantagens do manejo integrado das plantas daninhas em lavouras de café, destacam-se: produção de grande quantidade de material vegetal de lenta decomposição, aumento do teor de matéria orgânica, reciclagem de nutrientes, manutenção da umidade e da temperatura do solo e redução da sua erosão.

Há grande importância agronômica de algumas espécies vegetais encontradas entre as linhas do café, porém não se deve permitir o desenvolvimento delas junto à cultura, por reduzirem seu crescimento (Ronchi \& Silva, 2006), sendo recomendável o seu controle na linha, principalmente pela competição por nutrientes (Ronchi et al., 2003, 2007). Apesar das vantagens do manejo integrado de plantas daninhas, há muita carência de pesquisa científica sobre esse assunto, bem como poucas informações na literatura sobre a interferência de gramíneas e espécies com capacidade de fixação de $\mathrm{N}$, utilizadas na entrelinha da cultura do café. Esse grau de interferência pode variar de acordo com a espécie e a densidade de plantas (Ronchi et al., 2003), e a maioria das técnicas que vêm sendo desenvolvidas precisa ser ajustada para as diferentes condições de solo, clima e espécies competidoras.

Objetivou-se com este trabalho avaliar os efeitos da interferência de Digitaria horizontalis, Brachiaria decumbens, Brachiaria plantaginea e Mucuna aterrima, em diferentes densidades de infestação, sobre as características de crescimento de plantas jovens de café arábica. 


\section{MATERIAL E MÉTODOS}

O experimento foi conduzido em casa de vegetação com mudas de café Mundo Novo (linhagem 374/19), produzidas em sacolas por semeadura direta; no estádio de quatro a cinco pares de folhas completamente expandidas, elas foram transplantadas para vasos contendo $25 \mathrm{dm}^{3}$ de substrato. Como substrato, utilizouse terra de subsolo peneirada e esterco de curral curtido (3:1). Para fornecimento de $\mathrm{P}_{2} \mathrm{O}_{5}$, utilizou-se superfosfato simples (100 g por vaso), além de calcário dolomítico, a fim de elevar a saturação por bases a $60 \%$. Após o plantio das mudas, os vasos foram mantidos sob sistema de irrigação por aspersão. Adicionou-se $\mathrm{K}_{2} \mathrm{O}$ (31,48 g por vaso) e $\mathrm{N}$ (10 g por vaso) parcelados aos 30 e 60 dias após o transplantio. O solo utilizado foi Latossolo VermelhoAmarelo, cujas características físicas foram: classe textural: argiloarenosa; análise granulométrica, em dag $\mathrm{kg}^{-1}$ : areia -46 , silte -5 e argila - 49. As características químicas foram: $\mathrm{pH}$ água: 4,7; $\mathrm{P}: 2,3 \mathrm{mg} \mathrm{dm}^{-3} ; \mathrm{K}$ : $48 \mathrm{mg} \mathrm{dm}{ }^{-3} ; \mathrm{Al}^{+3}: 0,6 \mathrm{cmol}_{\mathrm{c}} \mathrm{dm}^{-3} ; \mathrm{H}+\mathrm{Al}$ : $6,27 \mathrm{cmol}_{\mathrm{c}} \mathrm{dm}^{-3} ; \mathrm{Ca}^{+2}: 1,4 \mathrm{cmol}_{\mathrm{c}} \mathrm{dm}^{-3} ; \mathrm{Mg}^{+2}$ : $0,4 \mathrm{cmol}_{\mathrm{c}} \mathrm{dm}^{-3}$; SB: $1,92 \mathrm{cmol}_{\mathrm{c}} \mathrm{dm}^{-3}$; t: 2,52; T: 8,19; P-rem: 24,3 $\mathrm{mg} \mathrm{L}^{-1}$; V: 23,00\%; m: 24\%; e MO: 2,4 dag $\mathrm{kg}^{-1}$.

O experimento foi instalado em blocos casualizados em esquema fatorial ( 4 x 4), com quatro espécies de plantas daninhas (D. horizontalis, $B$. decumbens, B. plantaginea e $M$. aterrima) e quatro densidades de infestação (zero, duas, quatro e seis plantas por vaso), com quatro repetições. A parcela experimental foi constituída de um vaso, contendo uma planta de café isolado ou em competição com as espécies mencionadas.

Após 60 dias de cultivo do café nos vasos, foi realizado o transplantio ou semeadura das espécies de plantas daninhas nos vasos. As espécies $D$. horizontalis, $B$. decumbens e $B$. plantaginea foram semeadas em bandejas de plástico, utilizando-se areia lavada como substrato para germinação das sementes. Sementes de $M$. aterrima foram semeadas diretamente nos vasos na mesma época da semeadura das gramineas nas bandejas.

No dia do transplantio das plantas daninhas para o vaso (0 DAT) e no dia do encerramento do experimento (90 DAT), determinaram-se a altura, a área de folhas de acordo com Antunes et al. (2008) e o diâmetro do caule da planta de café. O período de convivência entre a planta de café e as plantas daninhas foi considerado entre a emergência ou transplantio das plantas daninhas até o florescimento das gramíneas, o que ocorreu em, aproximadamente, 90 dias.

Na colheita do experimento, realizada aos 90 DAT, as plantas de café foram seccionadas rente ao solo, sendo separadas em folhas, caule e raízes, e as daninhas, separadas em parte aérea e sistema radicular. Nas raízes das plantas de café, determinou-se a densidade de raízes, medida por meio da razão entre a massa da matéria fresca das raízes e o volume de água deslocado $\left(\mathrm{g} \mathrm{mL}^{-1}\right)$ quando submersa, em proveta graduada de $1.000 \mathrm{~mL}$. As plantas de café e as plantas daninhas foram secas em estufa de circulação forçada de $\operatorname{ar}\left(65 \pm 3{ }^{\circ} \mathrm{C}\right)$ até atingirem massa constante, para determinação da matéria seca. Em seguida, estimaramse: razão de massa foliar (matéria seca foliar/ matéria seca total, $\mathrm{g} \mathrm{g}^{-1}$ ), razão de massa caulinar (matéria seca caulinar/matéria seca total, $\mathrm{g} \mathrm{g}^{-1}$ ), razão de massa radicular (matéria seca radicular/matéria seca total, $\mathrm{g} \mathrm{g}^{-1}$ ), razão de área foliar (área foliar/matéria seca total, $\mathrm{m}^{2} \mathrm{~g}^{-1}$ ) e razão do sistema radicular e parte aérea (matéria seca do sistema radicular/ matéria seca parte aérea, $\mathrm{g} \mathrm{g}^{1}$ ).

Para interpretação dos resultados, empregou-se a análise de variância, utilizando-se o teste $\mathrm{F}(p \leq 0,05$ de probabilidade de erro). Efetuou-se o desdobramento da interação significativa, empregando-se o teste de Tukey a $5 \%$ de probabilidade para as comparações entre espécies, e a análise de regressão para as densidades das plantas daninhas, com escolha dos modelos baseada na sua significância, no fenômeno biológico e no coeficiente de determinação $\left(\mathrm{R}^{2}=\mathrm{S} . \mathrm{Q}\right.$. Reg./S.Q. Trat.).

\section{RESULTADOS E DISCUSSÃO}

Verificou-se menor crescimento do café com o aumento da densidade de $B$. decumbens, $D$. horizontalis, B. plantaginea e $M$. aterrima, após 90 dias de convivência. Entre as gramíneas, B. plantaginea foi a que mais alterou o crescimento das plantas de café, para a densidade de seis plantas por vaso. Nessa densidade, B. decumbens, D. horizontalis, 
B. plantaginea e $M$. aterrima promoveram redução da taxa de crescimento, com menor incremento de altura na ordem de 11,6, 9,7, 16,1 e $28,1 \mathrm{~cm}$, respectivamente, quando comparadas com as plantas livres da competição (Tabela 1 e Figura 1).

As plantas de café com menor incremento da área foliar foram as que conviveram com $M$. aterrima e B. plantaginea, apresentando redução exponencial com o aumento da densidade de plantas daninhas (Figura 1). Na densidade de seis plantas daninhas por vaso, observou-se redução no crescimento das plantas de café de $38 \%$ e $33 \%$ para $M$. aterrima e B. plantaginea, respectivamente (Figura 1 e Tabela 1). Contudo, o aumento na densidade das plantas daninhas parece afetar mais severamente as plantas de café quando em convivência com $B$. decumbens, pois a taxa de queda na área foliar é fixa, sendo de aproximadamente $72 \mathrm{~cm}^{2}$ por unidade de planta em competição (Figura 1). Nesse sentido, apesar de $M$. aterrima e $B$. plantaginea proporcionarem menor desenvolvimento de área foliar nas plantas de café, não se observa essa mesma tendência com o aumento da densidade de plantas (Figura 1). A área foliar é a característica morfológica mais importante relacionada à capacidade das plantas de cobrir o solo e, principalmente, em termos de aproveitamento da radiação fotossintética (Fleck et al., 2009). Dias et al. (2005), analisando a interferência de Commelina sp. no cafeeiro, verificaram que a área foliar foi a caracteristica mais afetada pelas plantas daninhas (redução de 53,4\%).

Tabela 1 - Variáveis de crescimento de plantas jovens de café em competição com plantas daninhas nas densidades ${ }^{1 /}$ de $0,2,4$ e 6 plantas por vaso, após 90 dias de convivência

\begin{tabular}{|c|c|c|c|c|c|c|c|c|}
\hline \multirow{3}{*}{ Tratamento } & \multicolumn{8}{|c|}{ Variáveis ${ }^{\underline{2}}$} \\
\hline & IA & MST & MSC & MSF & MSR & \multirow{2}{*}{$\frac{\text { IAF }}{\left(\mathrm{cm}^{2}\right)}$} & \multirow{2}{*}{$\frac{\mathrm{DC}}{(\mathrm{mm})}$} & \multirow{2}{*}{$\frac{\mathrm{DR}}{\left(\mathrm{g} \mathrm{mL}^{-1}\right)}$} \\
\hline & \multicolumn{3}{|c|}{$(\mathrm{cm})$} & \multicolumn{2}{|c|}{ (g) } & & & \\
\hline \multicolumn{9}{|c|}{ Densidade 0} \\
\hline B. decumbens & $35,6 \mathrm{a}$ & $65,8 \mathrm{a}$ & $24,3 \mathrm{a}$ & $24,3 \mathrm{a}$ & $17,2 \mathrm{a}$ & $1.661,6 \mathrm{a}$ & $6,8 \mathrm{a}$ & $0,57 \mathrm{a}$ \\
\hline D. horizontalis & $35,8 \mathrm{a}$ & $66,4 \mathrm{a}$ & $25,0 \mathrm{a}$ & $24,7 \mathrm{a}$ & $17,1 \mathrm{a}$ & $1.707,6 \mathrm{a}$ & $6,9 \mathrm{a}$ & $0,54 \mathrm{a}$ \\
\hline B. plantaginea & $36,2 \mathrm{a}$ & $67,0 \mathrm{a}$ & $24,2 \mathrm{a}$ & $25,3 \mathrm{a}$ & $17,5 \mathrm{a}$ & $1.649,9 \mathrm{a}$ & $6,9 \mathrm{a}$ & $0,56 \mathrm{a}$ \\
\hline M. aterrima & $35,3 \mathrm{a}$ & $66,0 \mathrm{a}$ & $23,9 \mathrm{a}$ & $24,8 \mathrm{a}$ & $17,3 \mathrm{a}$ & $1.640,6 \mathrm{a}$ & $6,8 \mathrm{a}$ & $0,57 \mathrm{a}$ \\
\hline \multicolumn{9}{|c|}{ Densidade 2} \\
\hline B. decumbens & $30,7 \mathrm{a}$ & $57,4 \mathrm{a}$ & $21,4 \mathrm{a}$ & $23,6 \mathrm{a}$ & $12,4 \mathrm{a}$ & $1.401,1 \mathrm{a}$ & $7,1 \mathrm{a}$ & $0,38 \mathrm{~b}$ \\
\hline D. horizontalis & $30,5 \mathrm{a}$ & $58,6 \mathrm{a}$ & $22,3 \mathrm{a}$ & $21,8 \mathrm{a}$ & $14,5 \mathrm{a}$ & $1.484,0 \mathrm{a}$ & $5,8 \mathrm{a}$ & $0,49 \mathrm{a}$ \\
\hline B. plantaginea & $26,6 \mathrm{a}$ & $54,4 \mathrm{a}$ & $20,1 \mathrm{a}$ & $21,1 \mathrm{a}$ & $13,2 \mathrm{a}$ & $1.207,0 \mathrm{ab}$ & $5,9 \mathrm{a}$ & $0,44 \mathrm{a}$ \\
\hline M. aterrima & $16,0 \mathrm{~b}$ & $40,7 \mathrm{~b}$ & $13,8 \mathrm{~b}$ & $17,2 \mathrm{~b}$ & $9,7 \mathrm{~b}$ & $1.099,6 \mathrm{~b}$ & $3,9 \mathrm{~b}$ & $0,39 \mathrm{~b}$ \\
\hline \multicolumn{9}{|c|}{ Densidade 4} \\
\hline B. decumbens & $24,1 \mathrm{a}$ & $59,1 \mathrm{a}$ & $19,7 \mathrm{a}$ & $19,9 \mathrm{a}$ & $9,5 \mathrm{a}$ & $1.323,5 \mathrm{a}$ & $6,3 \mathrm{a}$ & $0,32 \mathrm{a}$ \\
\hline D. horizontalis & $28,3 \mathrm{a}$ & $48,0 \mathrm{a}$ & $20,9 \mathrm{a}$ & $17,5 \mathrm{ab}$ & $9,6 \mathrm{a}$ & $1.231,4 \mathrm{a}$ & $5,0 \mathrm{a}$ & $0,34 \mathrm{a}$ \\
\hline B. plantaginea & $25,4 \mathrm{a}$ & $48,3 \mathrm{a}$ & $18,3 \mathrm{a}$ & $20,2 \mathrm{a}$ & $9,8 \mathrm{a}$ & $1.130,1 \mathrm{ab}$ & $6,0 \mathrm{a}$ & $0,35 \mathrm{a}$ \\
\hline M. aterrima & $14,7 \mathrm{~b}$ & $36,4 \mathrm{~b}$ & $13,4 \mathrm{~b}$ & $14,9 \mathrm{~b}$ & $8,1 \mathrm{a}$ & $1.021,0 \mathrm{~b}$ & $3,7 \mathrm{~b}$ & $0,34 \mathrm{a}$ \\
\hline \multicolumn{9}{|c|}{ Densidade 6} \\
\hline B. decumbens & $24,0 \mathrm{a}$ & $41,3 \mathrm{a}$ & $14,7 \mathrm{ab}$ & $17,7 \mathrm{a}$ & $8,9 \mathrm{a}$ & $1.206,5 \mathrm{a}$ & $6,5 \mathrm{a}$ & $0,31 \mathrm{a}$ \\
\hline D. horizontalis & $26,1 \mathrm{a}$ & $41,6 \mathrm{a}$ & $16,4 \mathrm{a}$ & $17,3 \mathrm{a}$ & $7,9 \mathrm{a}$ & $1.230,1 \mathrm{a}$ & $4,9 \mathrm{~b}$ & $0,31 \mathrm{a}$ \\
\hline B. plantaginea & $20,1 \mathrm{~b}$ & $39,7 \mathrm{a}$ & $17,6 \mathrm{a}$ & $14,9 \mathrm{ab}$ & $7,2 \mathrm{a}$ & $1.107,3 \mathrm{ab}$ & $4,3 \mathrm{~b}$ & $0,23 \mathrm{~b}$ \\
\hline M. aterrima & $7,2 \mathrm{c}$ & $31,4 \mathrm{~b}$ & $12,9 \mathrm{~b}$ & $11,7 \mathrm{~b}$ & $6,8 \mathrm{a}$ & $1.018,6 \mathrm{~b}$ & $3,5 \mathrm{c}$ & $0,26 \mathrm{~b}$ \\
\hline ESP*DEN & $*$ & $* *$ & $*$ & $* *$ & $*$ & $* *$ & $*$ & $*$ \\
\hline $\mathrm{CV} \%$ & 9,61 & 12,2 & 10,8 & 9,5 & 10,2 & 9,7 & 13,2 & 13,2 \\
\hline
\end{tabular}

1/ Para cada densidade de plantas daninhas, médias seguidas pela mesma letra na coluna não diferem entre si pelo teste de Tukey $(P>0,05$ e 0,01$) .{ }^{*}, *$ significativo a $1 \%$ e $5 \%$, respectivamente ${ }^{2 /}$ IA- incremento em altura, MST- matéria seca total, MSC- matéria seca do caule, MSF- matéria seca de folhas, MSR- matéria seca do sistema radicular, IAF- incremento de área foliar, DC- diâmetro do coleto, DR- densidade radicular, CV- coefíciente de variação. 

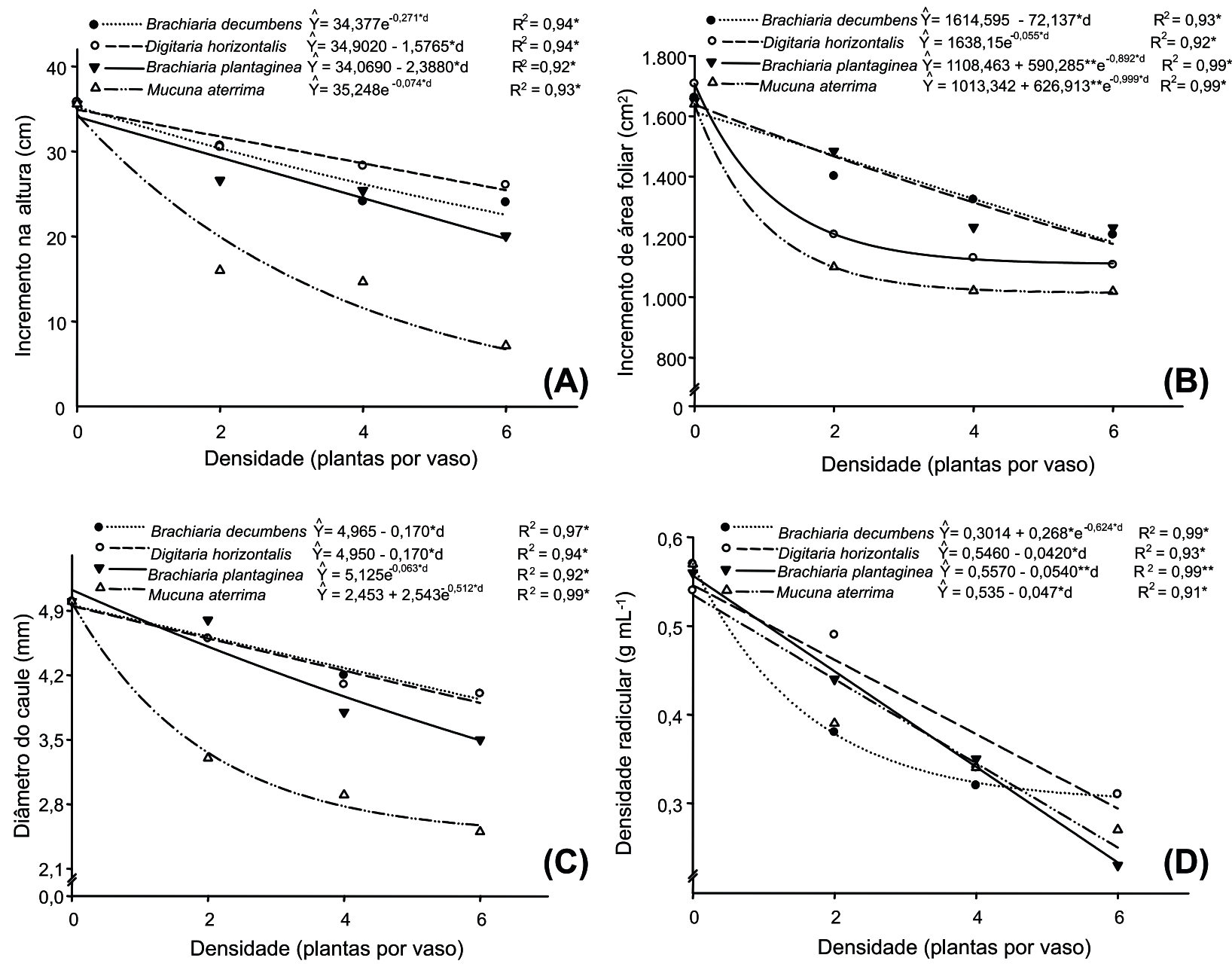

$*, * * ; \mathrm{P}<0,05$ e $\mathrm{P}<0,01$, respectivamente.

Figura 1 - Incremento na altura (A), incremento de área foliar(B), diâmetro do caule (C) e densidade radicular(D) de plantas de café em função da densidade de plantas daninhas após 90 dias de convivência no vaso.

Observou-se menor incremento no diâmetro do caule do café que conviveu com as espécies daninhas, sendo $B$. decumbens a espécie que menos afetou essa variável na maior densidade estudada. À medida que aumentou a densidade de plantas daninhas, houve redução linear dessa variável para $B$. decumbens e D. horizontalis e exponencial para $B$. plantaginea e $M$. aterrima (Figura 1). Digitaria horizontalis, B. plantaginea e $M$. aterrima proporcionaram menor desenvolvimento do diâmetro do caule - na ordem de 2,0, 2,6 e 3,3 $\mathrm{mm}$, respectivamente - em comparação com as plantas de café livres da interferência das plantas daninhas (Tabela 1). Em trabalhos realizados por Ronchi \& Silva
(2006), houve menor valor para o diâmetro do caule das plantas de café que conviveram com Leonurus sibiricus, Richardia brasiliensis e Bidens pilosa; esta última reduziu em $29 \%$ o diâmetro do caule na densidade de cinco plantas por vaso, em 77 dias de convivência. Contudo, para outras espécies, como Brachiaria decumbens, Commelina diffusa, Nicandra physaloides e Sida rhombifolia, não se verificou efeito sobre as plantas de café. Em trabalhos similares com plantas de café, utilizando vasos de $12 \mathrm{dm}^{3}$ e densidade de 75 plantas $\mathrm{m}^{-2}$, podese ter superestimado a competição das plantas daninhas, devido à limitação do vaso, associado ao tempo de cultivo prolongado (Ronchi \& Silva, 2006; Ronchi et al., 2007). 
Observou-se relação negativa entre a densidade radicular e a densidade das plantas daninhas, sendo ajustado modelo exponencial para $B$. decumbens e linear para as demais espécies (Figura 1). Para cada planta de $D$. horizontalis, B. plantaginea e $M$. aterrima em competição houve menor densidade radicular do café - na ordem de 0,042, 0,054 e $0,047 \mathrm{~g} \mathrm{~mL}^{-1}$. As plantas de café que conviveram com $B$. plantaginea e $M$. aterrima obtiveram menor densidade radicular: 0,23 e $0,26 \mathrm{~g} \mathrm{~mL}^{-1}$ respectivamente; para as plantas que se desenvolveram sem a interferência de plantas daninhas os valores da densidade radicular foram de 0,56 e $0,57 \mathrm{~g} \mathrm{~mL}^{-1}$, respectivamente (Tabela 1 ).
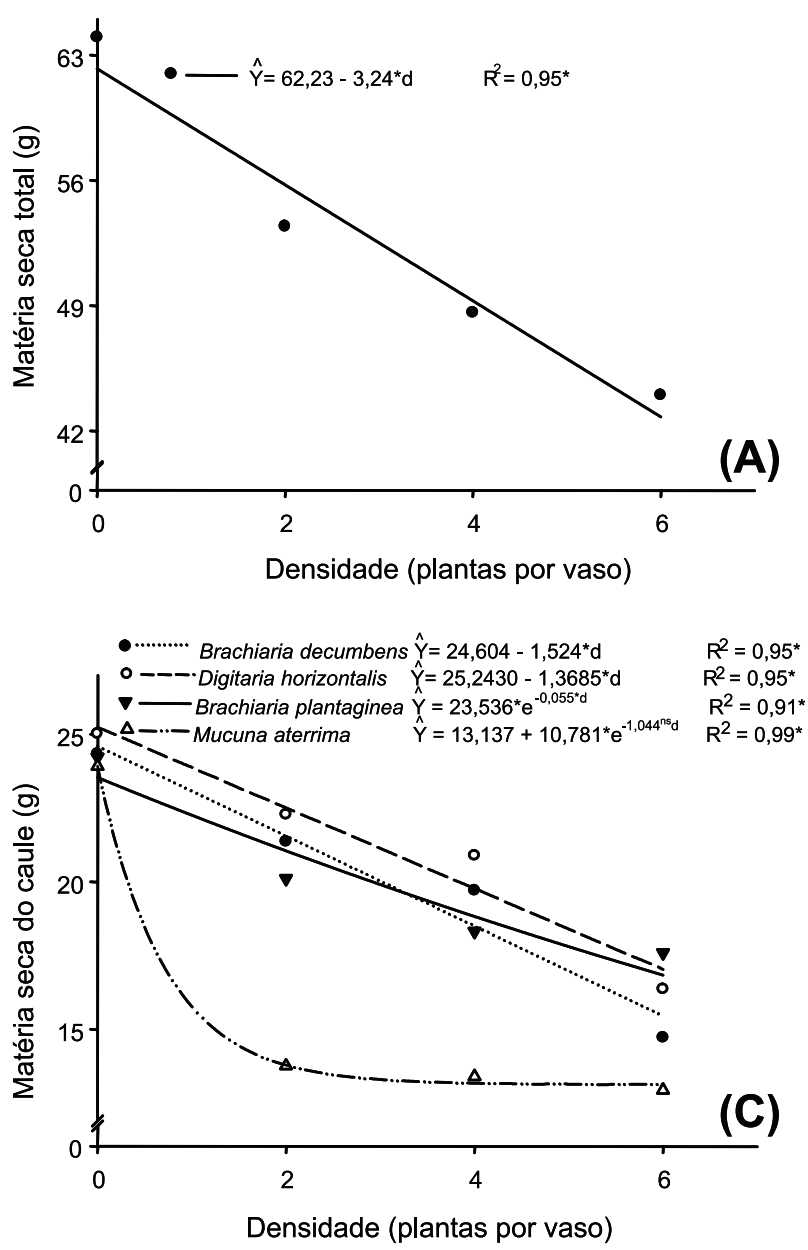

Plantas de café submetidas à maior densidade de plantas daninhas apresentaram menor matéria seca total, com diferença de $37,3 \%$ para as que conviveram com D. horizontalis; $37,8 \%$ para $B$. decumbens; $40,2 \%$ para $B$. plantaginea e $52,7 \%$ para $M$. aterrima, comparativamente às plantas livres da interferência das plantas daninhas (Tabela 1 e Figura 2). Na Figura 2, observa-se menor produção de matéria seca total das plantas de café, de 3,24 g para cada planta daninha adicionada ao vaso, havendo ajuste a modelo linear com o aumento da densidade de planta daninha, independentemente da espécie.
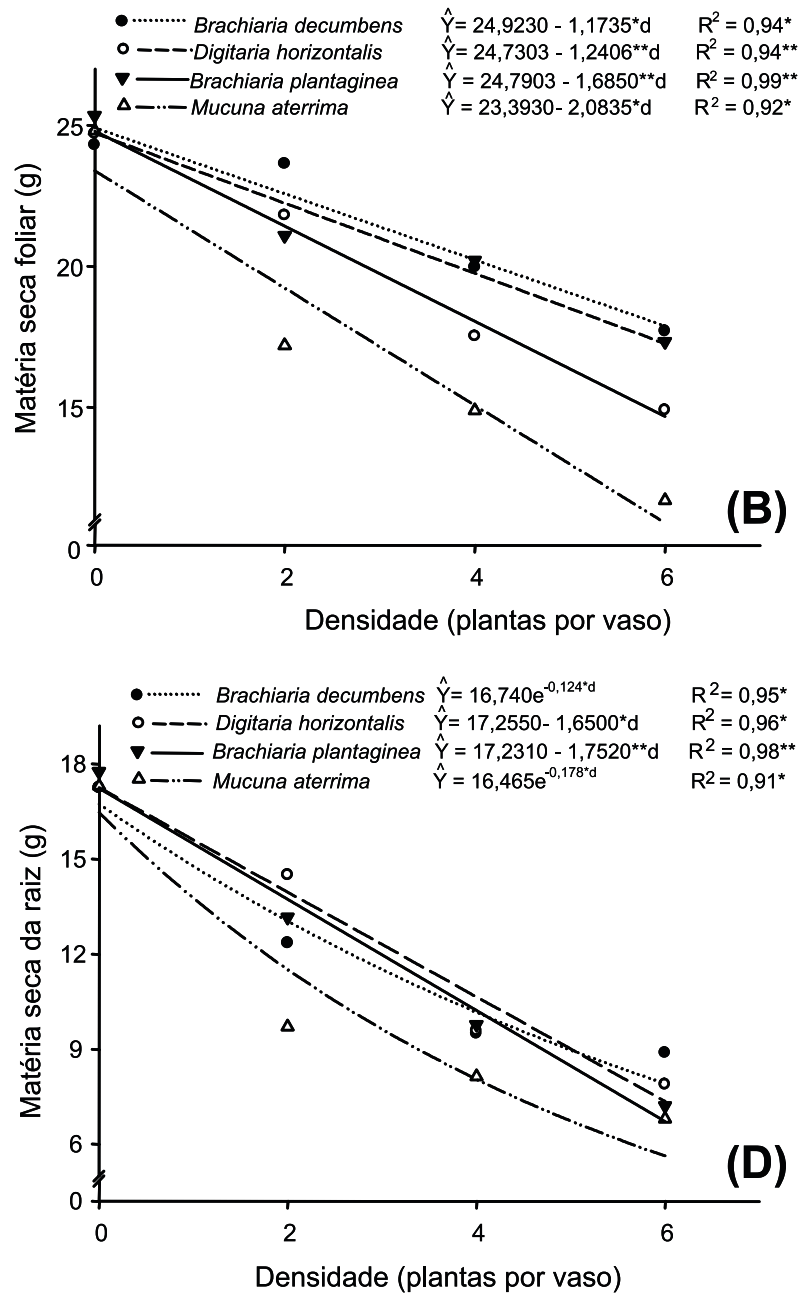

***; $\mathrm{P}<0,05$ e $\mathrm{P}<0,01$, respectivamente

Figura 2 - Matéria seca total (A), matéria seca foliar (B), matéria seca do caule (C) e matéria seca da raiz (D) de plantas de café em função da densidade de plantas daninhas após 90 dias de convivência no vaso. 
Na densidade de duas plantas por vaso, $M$. aterrima foi a espécie que mais alterou o acúmulo de matéria seca das folhas do café (Tabela 1). Com a maior densidade de plantas daninhas, houve menor matéria seca foliar do café, na ordem de 7,04, 7,44, 10,1 e 12,5 g para as espécies $B$. decumbens, $D$. horizontalis, $B$. plantaginea e $M$. aterrima, respectivamente, em relação àquelas que se desenvolveram livres de plantas daninhas. Verificou-se redução linear da matéria seca das folhas com o aumento da densidade de plantas daninhas, com destaque para $M$. aterrima, que causou redução de $2,08 \mathrm{~g}$ por cada planta daninha adicionada ao vaso (Figura 2 ).

Observou-se redução exponencial da matéria seca do caule de plantas de café em competição com $M$. aterrima, com redução de $42,25 \%$ dessa variável nas plantas de café que se desenvolveram com duas plantas competidoras. Em baixa densidade, M. aterrima ocasionou grande interferência negativa e, com o aumento da densidade, essa variável tendeu a se estabilizar (Figura 2). As gramineas, $B$. decumbens e $D$. horizontalis, ocasionaram redução linear da matéria seca do caule com o aumento da densidade, sendo de 1,5 e $1,3 \mathrm{~g}$ de caule, respectivamente, para cada planta daninha adicionada ao vaso (Figura 2). Dias et al. (2005) observaram redução de $44,8 \%$ da matéria seca do caule do café que conviveu com Commelina bengalensis.

A matéria seca de raiz do café apresentou redução exponencial quando se desenvolveu $\operatorname{com} B$. decumbens e $M$. aterrima. Em convivio com $D$. horizontalis e $B$. plantaginea, houve redução linear da matéria seca de raízes, sendo de 1,6 e 1,7 g, respectivamente, para cada planta adicionada ao vaso. Nas densidades de quatro e seis plantas daninhas não houve diferença da matéria seca de raízes do café, independentemente da espécie. $\mathrm{Na}$ densidade de seis plantas daninhas, houve redução de até $55 \%$ desta variável para as plantas de café que conviveram com $B$. plantaginea e $M$. aterrima (Tabela 1).

Quanto às variáveis razão de massa foliar, razão de massa radicular e razão de área foliar, houve efeito significativo para a densidade de plantas daninhas, não ocorrendo diferença entre as espécies. Com o aumento da densidade de plantas daninhas, houve aumento linear da razão de massa foliar, redução da razão de massa radicular e não houve efeito significativo para a razão de massa caulinar do café (Figura 3). Para cada planta daninha adicionada ao vaso, houve aumento de $0,0051 \mathrm{~g} \mathrm{~g}^{-1}$ na razão de massa foliar de plantas de café. Entretanto, observouse redução linear de $0,006 \mathrm{~g} \mathrm{~g}^{-1}$ na razão de massa radicular com o aumento das plantas daninhas nos vasos (Figura 3).

Com o aumento da densidade de plantas daninhas, houve maior alocação para a parte aérea e menor alocação de fotoassimilados para o sistema radicular das plantas de café. Essa alocação foi relativamente maior para as folhas, uma vez que o decréscimo no acúmulo de matéria seca de caule segue a redução observada para massa seca total, enquanto nas folhas a diminuição foi menor do que a observada em toda a planta (Tabela 1). Houve incremento linear na razão de área foliar com o aumento da densidade de plantas daninhas (Figura 3), podendo ser consequência da competição por luz na parte aérea e/ou limitação nutricional. O sombreamento faz com que as folhas se expandam mais por unidade de área (folhas maiores), porém, consequentemente, elas ficam mais finas (Radin et al., 2004).

As alterações morfológicas observadas levaram à redução da razão sistema radicular/parte aérea do café, com o aumento da densidade de plantas daninhas (Figura 3). A partir dessa razão, pode-se inferir que, sob competição, houve menor alocação de fotoassimilados para o sistema radicular em relação à parte aérea das plantas de café.

Segundo Rajcan \& Swanton (2001), em resposta à competição, pode haver alterações na partição de fotoassimilados, com mudanças morfológicas na planta, como reduções na proporção de matéria seca de raízes em relação à parte aérea, na fase inicial de desenvolvimento da cultura. Essa é uma tentativa da planta de investir em determinado compartimento, devido à maior carência de recurso (Poorter \& Nagel, 2000), como observado para milho em competição com plantas de Amaranthus retroflexus, que apresentou redução da razão sistema radicular/parte aérea (Liu et al., 2008).

Planta Daninha, Viçosa-MG, v. 29, n. 1, p. 137-147, 2011 

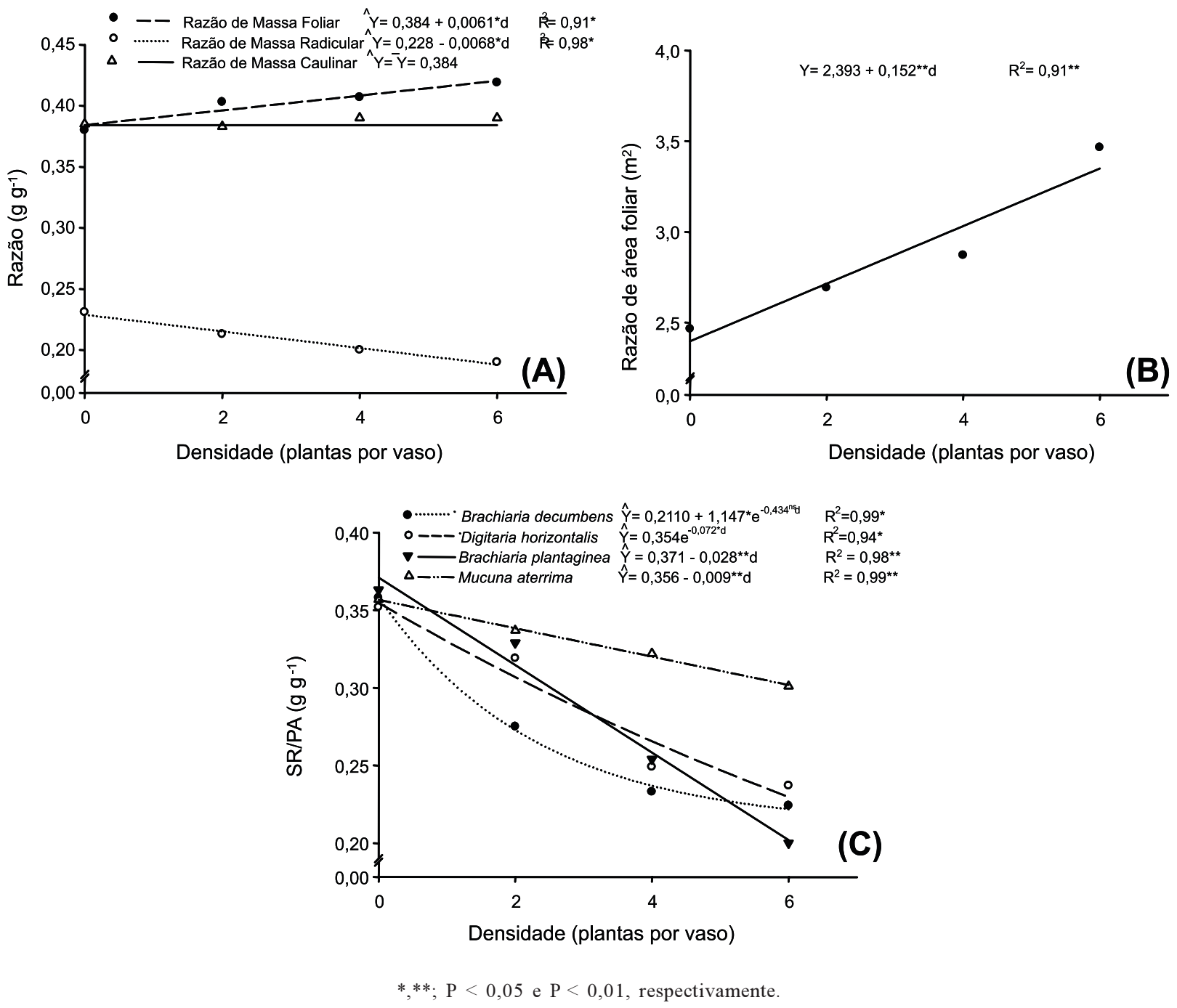

Figura 3 - Razão de massa foliar, caulinar e radicular (A), razão de área foliar (B), razão sistema radicular/parte aérea (SR/PA) (C) de plantas de café em função da densidade de plantas daninhas após 90 dias de convivência no vaso.

No tocante relação às características das plantas daninhas, a matéria seca da parte aérea variou com a espécie e com a densidade (Figura 3); as gramineas tiveram tendência de manter o acúmulo de matéria seca mesmo com o aumento da densidade de plantas. Segundo Ronchi \& Silva (2006), as espécies Leonorus sibiricus e Richardia brasiliensis, cultivadas em vaso em competição com o cafeeiro, não tiveram o acúmulo de matéria seca afetado pela densidade. O crescimento inicial das plantas daninhas diminui com o aumento da densidade, ou seja, em baixas densidades, a produção total de biomassa é determinada por poucas plantas maiores, e em altas densidades, por muitas plantas menores. Todavia,
M. aterrima comportou-se de forma diferente: apresentou aumento da matéria seca da parte aérea com o aumento da densidade (Figura 3).

$\mathrm{O}$ acúmulo de matéria seca do sistema radicular das plantas daninhas na maior densidade foi de 44,1, 32,3, 61,7 e 15,2 $\mathrm{g}$ para $B$. decumbens, $D$. horizontalis, $B$. plantaginea e $M$. aterrima, respectivamente; esta última apresentou maior interferência nas plantas de café (Figura 3).

Quando se compara a quantidade de matéria seca da raiz acumulada pelas plantas daninhas (Figura 4) com a acumulada pelo café (Tabela 1 e Figura 3), no mesmo vaso, verifica-se que $B$. decumbens, $D$. horizontalis, 
B. plantaginea e $M$. aterrima acumularam, respectivamente, 4,9, 4,1, 8,5 e 2,2 vezes mais matéria seca de raiz que o cafeeiro na maior densidade de plantas daninhas. O menor desenvolvimento do sistema radicular das plantas de café pode estar relacionado ao maior acúmulo de matéria seca das raízes de plantas daninhas, devido à sua maior habilidade competitiva por nutrientes. Guimarães et al. (1996) destacam a importância da quantidade de raízes na capacidade de absorção de água e de nutrientes pela planta, podendo ser utilizadas diferentes correlações entre a produção de raízes e a produtividade das plantas.

Existem diferenças na competitividade, entre espécies vegetais, pelos recursos encontrados abaixo e acima da superficie do solo. Essas diferenças, aparentemente, se devem à maior alocação de fotoassimilados para as raízes e, consequentemente, maior alocação de matéria seca radicular (Cahill Jr., 2003). Estudos de competição inicial entre plantas daninhas e cultura, baseados no crescimento quantitativo das raízes, indicaram que elas representam o principal órgão de competitividade das plantas daninhas (Dotray \& Young, 1993). Em arroz, o rápido crescimento do sistema radicular da cultura associa-se com sua maior competitividade na fase inicial de desenvolvimento. No entanto, o envolvimento da parte aérea na habilidade competitiva com plantas daninhas aumenta progressivamente com o tempo, tornando-se mais importante nas fases mais avançadas de desenvolvimento (Fofana \& Rauber, 2000).

Apesar de $M$. aterrima ser a espécie com menor acúmulo de matéria seca radicular entre as plantas daninhas estudadas (Figura 5), a produção de raiz da planta de café foi afetada de forma semelhante à daquelas que competiram com as outras espécies daninhas. Esse fato pode ser devido ao maior sombreamento dessa espécie, ocorrendo forte competição por luz com a planta de café, pois a intensa competição acima do solo, por luz, restringirá o fluxo de carboidratos para as raízes, alterando tanto o crescimento da parte aérea quanto o radicular.

Os efeitos negativos das plantas daninhas sobre o cafeeiro foram provocados provavelmente pela competição por nutrientes (Ronchi et al., 2003; Silva \& Ronchi et al., 2004), luz
(Alfonsi et al., 2005), espaço físico, entre vários outros fatores. Das espécies estudadas, $M$. aterrima foi a que mais afetou o crescimento do cafeeiro (altura de plantas, área foliar, matéria seca do caule e das folhas e diâmetro do coleto), mesmo em baixas densidades. Isso

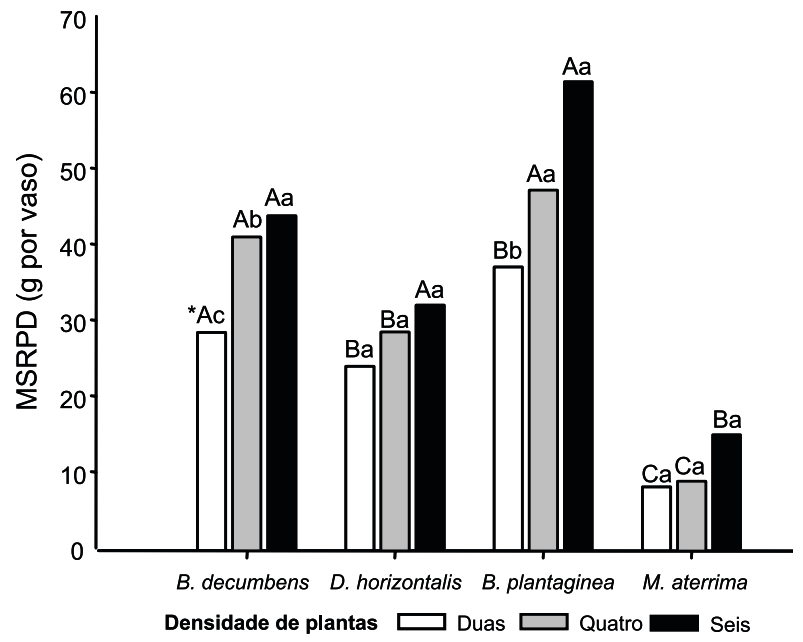

Médias seguidas pela mesma letra minúscula para cada espécie não diferem entre si, seguidas pela mesma letra maiúscula para cada densidade não diferem entre si, pelo teste de Tukey, a 5\% de significância.

Figura 4 - Matéria seca do sistema radicular de plantas daninhas (MSRPD) com diferentes densidades, após 90 dias de convivência com plantas de café

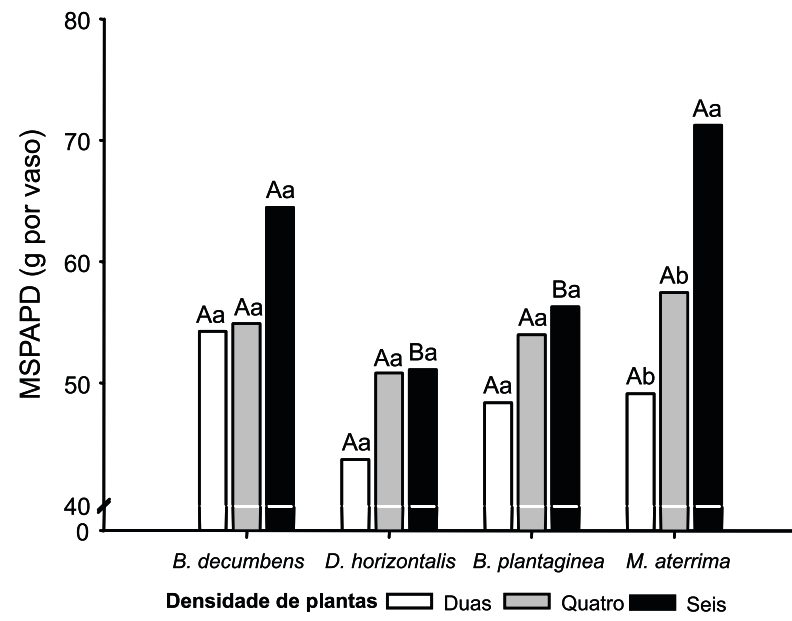

Médias seguidas pela mesma letra maiúscula para cada densidade não diferem entre si, médias seguidas pela mesma letra minúscula para cada espécie não diferem entre si, pelo teste de Tukey, a 5\% de significância.

Figura 5 - Matéria seca da parte aérea de plantas daninhas (MSPAPD) em diferentes densidades após 90 dias de convivência com plantas de café 
ocorreu provavelmente em razão de suas características, como alta agressividade inicial, alto volume de massa verde e crescimento trepador, o que leva ao sombreamento da cultura, sendo necessários cuidados no manejo da espécie em lavouras de café. Esse crescimento rápido é característica importante no processo de supressão de plantas daninhas, o que lhes propicia vantagem na competição pela luz, possibilitando sombrear a espécie de menor porte. Segundo Bergo et al. (2006), cafezais em formação tiveram sua altura, diâmetro de copa e crescimento afetados pela leguminosa Canavalia ensiformes.

Tanto $M$. aterrima como o café apresentam metabolismo $\mathrm{C}_{3}$, porém $M$. aterrima apresenta crescimento inicial mais rápido que o das plantas jovens de café, levando ao sombreamento destas. Apesar de ter evoluído em ambientes sombreados, o café demonstra baixa capacidade de aclimatação em ambientes com reduzida disponibilidade de luz (Chaves et al., 2008). Portanto, $M$. aterrima possui alto poder competitivo quando se desenvolve na linha do café, porém, se manejada adequadamente, pode ser utilizada pelos cafeicultores na entrelinha para a supressão de outras plantas daninhas, proporcionando boa cobertura do solo, reciclagem de nutrientes e efeitos alelopáticos (Monqueiro et al., 2009). A ação alelopática, tanto durante o crescimento vegetativo como durante o processo de decomposição, exerce inibição interespecifica sobre outras espécies. No entanto, na prática, é difícil distinguir se os efeitos de uma planta sobre a outra se devem à alelopatia ou à competição (Fuerst \& Putnan, 1983).

Entre as gramineas, B. plantaginea foi a que mais reduziu as características de crescimento do café, principalmente nos tratamentos com densidades maiores, com destaque para a redução no incremento de altura, no índice de área foliar, no diâmetro do coleto e na densidade radicular. Foi também a espécie que mais desenvolveu raízes. $B$. decumbens e $D$. horizontalis também ocasionaram redução do crescimento do café, mesmo em baixas densidades. É característica de espécies de metabolismo $\mathrm{C}_{4}$ como gramíneas, tornaremse altamente competitivas com espécies $\mathrm{C}_{3}$, como o café, sobretudo devido ao rápido crescimento e à capacidade de sombreamento ainda na fase inicial de desenvolvimento.
Há relação negativa entre a densidade de plantas daninhas em competição com plantas jovens de café e as variáveis de crescimento dessas plantas, evidenciando a necessidade de controle inicial das plantas daninhas na linha da cultura, principalmente pelo rápido crescimento e alta habilidade competitiva dessas espécies daninhas com a cultura do café. Em campo, nas plantações jovens de café, as densidades de plantas daninhas são muito superiores às estudadas (até 64 plantas $\mathrm{m}^{-2}$ ), podendo haver efeitos semelhantes aos encontrados neste trabalho, com atraso no desenvolvimento do cafeeiro e posterior redução da produtividade. É de grande importância a condução de trabalhos em campo para mais informações sobre a interferência dessas plantas daninhas em lavouras jovens de café.

\section{LITERATURA CITADA}

ALFONSI, E. L. et al. Crescimento, fotossíntese e composição mineral em genótipos de Coffea com potencial para utilização como porta-enxerto. Bragantia, v. 64, n. 1, p. 1-13, 2005.

ANTUNES, W. C. et al. Allometric models for nondestructive leaf area estimation in coffee (Coffea arabica and Coffea canephora). Ann. Appl. Biol., v. 59, n. 1, p. 1-8, 2008.

BAUMANN, D. T.; BASTIAANS, L.; KROPFF, M. J. Competition and crop performance in a leek-celery intercropping system. Crop Sci., v. 41, n. 3, p. 764-774, 2001.

BERGO, C. L. et al. Avaliação de espécies leguminosas na formação de cafezais no segmento da agricultura familiar no Acre. Acta Amaz., v. 36, n. 1, p. 19-24, 2006.

CAHILL Jr., J. F. Lack of relationship between below-ground competition and allocation to roots in 10 grassland species. J. Appl. Ecol., v. 91, p. 532-540, 2003.

CHAVES, A. R. M. et al. Seasonal chages in leaf photoprotective mechanismos of leaves from shaded and unshaded field-grown coffee (Coffea arabica L.) TreesStruct. Funct., v. 22, n. 3, p. 351-361, 2008.

COMPANHIA NACIONAL DE ABASTECIMENTO CONAB. Acompanhamento da safra brasileira. 2009. Disponível em: < http://www.conab.gov.br>. Acesso em: 25 set. 2009 .

DIAS, G. F. S. et al. Brachiaria decumbens supresses the initial growth of Coffea arabica. Sci. Agric., v. 61, n. 6, p. 579-583, 2004. 
DIAS, T. C. S.; ALVES, P. L. C. A.; LEMES, L. N. Períodos de interferência de Commelina bengalensis na cultura do café recém-plantada. Planta Daninha, v. 23, n. 3, p. 397-404, 2005.

DOTRAY, P. A.; YOUNG, F. L. Characterization of root and shoot development of jointed goatgrass (Aegilops cylindrica). Weed Sci., v. 41, n. 3, p. 353-361, 1993.

ERASMO, E. A. L.; PINHEIRO, L. L. A.; COSTA, N. V. Levantamento fitossociológico das comunidades de plantas infestantes em áreas de produção de arroz irrigado cultivado sob diferentes sistemas de manejo. Planta Daninha, v. 22, n. 2, p. 195-201, 2004.

FLECK, N. G. et al. Avaliação de características de planta em cultivares de aveia com habilidade competitiva.

Planta Daninha, v. 27, n. 2, p. 211-220, 2009.

FOFANA, B.; RAUBER, R. Weed suppression ability of upland rice under low-input conditions in West Africa. Weed Res., v. 40, n. 1, p. 271-280, 2000

FUERST, E. P.; PUTNAN, A. R. Separating the competitive and allelopathic components of interference: theoretical principles. J. Chem. Ecol., v. 9, n. 8, p. 937-944, 1983.

GUIMARÃES, C. M.; BRUNINI, O.; STONE, L. F. Adaptação do feijoeiro (Phaseolus vulgaris L.) à seca. 1. Densidade e eficiência radicular. Pes. Agropec. Bras., v. 31, n. 6, p. 393-399, 1996.

LIU, J. et al. Reproductive allocation patterns in different density populations of spring wheat. J. Integr. Plant Biol., v. 50, n. 2 , p. $141-146,2008$.

MONQUEIRO, P. A. Efeito de adubos verdes na supressão de espécies de plantas daninhas. Planta Daninha, v. 27, n. 1, p. $85-95,2009$
MORTENSEN, D. A.; BASTIAANS, L.; SATTIN, M. The role of ecology in the development of weed management systems: an outlook. Weed Res., v. 40, n. 1, p. 49-62, 2000.

POORTER, H.; NAGEL O. The role of biomass allocation in the growth response of plants to different levels of light, $\mathrm{CO}_{2}$, nutrients and water: a quantitative review. Austr. J. Plant.

Physiol., v. 27, n. 6, p. 595-607, 2000.

RADIN, B. et al. Crescimento de cultivares de alface conduzidas em estufa e no campo. Hortic. Bras., v. 22, n. 2, p. 178-181, 2004.

RAJCAN, I.; SWANTON, C. J. Understanding maize-weed competition: resource competition, light quality and the whole plant. Field Crop. Res., v. 71, n. 2, p. 139-150, 2001 .

RONCHI, C. P. et al. Acúmulo de nutrientes pelo cafeeiro sob interferência de plantas daninhas. Planta Daninha, v. 21, n. 2, p. 219-227, 2003.

RONCHI, C. P.; SILVA, A. A. Effects of weed species competition on the growth of young coffee plants. Planta Daninha, v. 24, n. 2, p. 415-423, 2006.

RONCHI, C. P.; TERRA, A. A.; SILVA, A. A. Growth and nutrient concentration in coffee root system under weed species competition. Planta Daninha, v. 25, n. 4, p. $679-687,2007$.

SOUZA, L. S. et al. Efeitos das faixas de controle do capimbraquiária (Brachiaria decumbens) no desenvolvimento inicial e na produtividade do cafeeiro (Coffea arabica).

Planta Daninha, v. 24, n. 4, p. 715-720, 2006.

TOLEDO, S. V.; MORAES, M. V.; BARROS, I. Efeito da freqüência de capinas na produção do cafeeiro. Bragantia, v. 55, n. 2 , p. $317-324,1996$. 